sand; water poured into this will gradually percolate through and moisten the sand.

For longevity experiments ticks are best kept in this way, observations being readily made through the glass without disturbing the ticks. These tubes may be kept outside inserted in the soil and the longevity of the stages determined under the prevailing or normal climatical conditions which, however, are not always the most favorable to longevity. In determining the longevity of ticks on grass and weeds, a screen cage is necessary to assure protection from accidental intrusion.

The life history of the Spinose Ear Tick, Ornithodoros megnini, has been determined by attaching to the ears of animals bags held in place and prevented from being rubbed off by tying to a cord about the horns.

\title{
SOME LIFE HISTORY NOTES ON THE SOUTHERN CATTLE TICK
}

(Illustrated with Lantern Slides.)

By E. C. Соттом, Knoxville, Tenn.

(Withdrawn for publication elsewhere.)

\section{A TENTATIVE LAW RELATING TO THE INCUBATION OF THE EGGS OF MARGAROPUS ANNULATUS}

By W. D. Hunter, Bureau of Entomology, U. S. Department of Agriculture.

Studies of the effects of temperatures upon insects have always held great interest and have frequently led to results of practical value. In this country the principal work has been done by Dr. L. O. Howard, who in 1896 in a paper read before this Association, "Some Temperature Effects on Household Insects," ’a pointed out exactly how cold storage practice could be utilized in the control of certain species. A year before, the same entomologist had shown the probabilities of the restriction of imported injurious species to certain life zones which, of course, are predetermined by temperatures. ${ }^{\text {b }}$ Later Doctor Howard in his paper on the geographical distribution of the yellow fever mosquito made much the most interesting and important contribution to the subject. ${ }^{c}$ He showed how the range of Stegomyia calopus was determined by temperature and how the exact limitations of the regions in which this mosquito, if accidentally introduced, might be expected to become perfectly established, could be determined by computing the accumulated effective temperature.

aBul. Bur. Ent. 6, p. 13-17.

bProc. Ent. Soc. Wash. 3: 219-226.

cPublic Health Rep'ts, 18, No. 46. 
The possibility of controlling Bruchids in stored cow-peas was shown in 1905 by Mr. J. W. T. Duvel.e

Prof. E. D. Sanderson in 1905 proposed a hypothesis regarding the determination of the time of maximum emergence from hibernation of the cotton boll weevil. ${ }^{\mathrm{d}}$ The proposed rule was based upon the departure of the temperature from the normal. The maximum emergence would be later or earlier than the normal time as the accumulated temperature would be lower or higher. The work on the boll weevil has furnished another example. Mr. W. O. Martin, formerly associated with Mr. Wilmon Newell, devised an ingenious method of determining the time when weevils in the dispersion movement had arrived in any certain field. ${ }^{\mathrm{P}}$ Previously it has been shown by Dr. W. E. Hinds and the writer that the growth of the weevil larva was regulated practically absolutely by effective temperatures and the amount of temperature necessary for the development of the different stages has been determined. Therefore the age of any weevil stage found in degrees of effective temperature was known. It only remained to sum up the daily effective temperature, going backward from the day upon which the specimens might be found until the total equalled the known amount necessary for that stage. The date thus obtained, of course, was the one upon which the parent weevil had reached the field.

There are two respects in which the cattle tick is conspicuously affected by temperatures: (1) its distribution in this country is limited; and (2) in a large portion of the natural range the eggs while not destroyed are prevented from hatching for several months during the winter. Attention was called by Doctor Howard to the restricted distribution of the tick and the close correspondence of its range to that of the yellow fever mosquito. In the present paper, however, we are concerned with the second feature, namely, the long deferred hatching due to low temperatures.

In work relating to the cattle tick, in which the writer is associated with Mr. W. A. Hooker, it was found that the total effective temperature required for hatching varied from 840 to 1510 degrees $\mathrm{F}$. The shortest incubation period was found when the accumulated effective temperature was highest and the longest incubation when the accumulated effective temperature was lowest. That is, the incubation period varied inversely with the accumulated effective temperature. Now, obviously the reason for the variation is the daily mean temperature. In other words, incubation takes longer in winter than in summer. What was desired then was to determine the rela-

dBul. Bur. Ent. 52, p. 29-42.

eBul. Bur. Ent. 54, p. 49-54.

fCir. La. Crop Pest Comm. 9, p. 23-27. 
tion between the daily mean temperature and the total effective required for hatching. An examination of careful records kept by Mr. Hooker extending over two entire years enables us to formulate the following tentative law: When the average daily mean temperature ranges less than 53.2 degrees, at least 1,510.8 degrees of effective temperature must accumulate before hatching will take place. When the mean daily temperature averages from $61.4^{\circ}$ to $77.8^{\circ}$, from 840.5 to 1,139.1 degrees of effective temperature will be required for hatching. When the mean daily temperature averages higher than 80 degrees, between 782.7 and 824.3 degrees of effective temperature must be accumulated before hatching will take place.

Practical Application.-In approximately one-half of the normally tick infested area in this country no eggs deposited after about the middle of September hatch until some indefinite time the following spring. The cultivated fields (and those from which cattle have been kept for some time) in this large area are absolutely free of ticks every fall. Infested cattle will soon lose their ticks when placed on such areas and will not become reinfested with the progeny of the dropped individuals until such time as the eggs may hatch. The law proposed will tell the farmer how long the eattle may remain without danger of infestation. There has been an indefinite rule to let cattle remain in such cases "until spring," but some seasons they should be removed in February and in others the pasture could be continued in use until May. One of the most important difficulties in the rotation system of freeing eattle of ticks is that farms are generally overstocked. The rule proposed will tend to minimize this obstacle by showing how pastures may be utilized until the latest safe date.

The following is proposed as the most feasible plan in placing the necessary information in the hands of farmers: let the state entomologist keep records of the daily mean and effective temperatures (or obtain them from the Weather Bureau) beginning with, say September 15 and starting separate computations at regular semi-monthly intervals. These dates will stand for the time when any farmer may have placed cattle in tick free areas. When the proposed law shows that the time for eggs to hatch is approaching, notice could be issued in the press. Such a notice might read in brief as follows: Farmers who placed cattle in tick free areas between September 15 and 30 should remove them by February 15; there is no danger of reinfestation of cattle placed on tick free pastures during October and will not be until further notice is given.

It is not at all improbable that individual ranchers could apply the rule by means of data obtained on their own places. In such 
cases, the results would be more exact because computations would begin on the exact date cattle were placed in the pastures, while those made in the office of the entomologist would necessarily be more or less generalized. The only apparatus necessary for the ranchman would be a set of maximum and minimum thermometers and the only work involved, the keeping of the record of the average daily mean temperature and the accumulated effective temperature from the date the cattle were placed on the tick free area.

Possible Criticisms. - The criticism might be made that studies referred to in the foregoing do not take into consideration factors other than temperature which might influence incubation. Among these might be mentioned: (1) moisture; and (2) accidental heat, as for instance from manure piles. Regarding moisture, it may be said that tick eggs are susceptible. A certain degree of dessication absolutely prevents hatching. Nevertheless our data have been drawn from eggs placed under a variety of conditions and due allowance has been made in the law for the usual seasonal variations. Our figures are not from individual lots of eggs, but averages from many lots under different conditions. The accidental heat from manure referred to at most could be but an exceedingly unimportant matter. About barns it might be worthy of consideration, but in pastures for all practical purposes it would be absolutely negligible.

There is a margin for possible error in the temperatures that may occur between the time a prediction is made and the actual time of hatching. Unusual variations may lengthen or shorten this interval. This obviously will always make it impossible to predict the exact time of hatching. Nevertheless, close approximations can be made and these will serve every practical purpose. The entomologist can always take pains to be on the safe side by allowing for the highest temperatures known for the period between the date of the prediction and the forecasted date of hatching.

In conclusion, it seems that the present proposed law is at least as tangible as any temperature law proposed with reference to insects. Strictly tentative as it is and subject to possible important modifications or even absolute nullification as the result of further data, at this time it seems to have practical possibilities. Though not as important as Doctor Howard's rule regarding the yellow fever mosquito, it is at least as definite, for the factors that could possibly vitiate it are no more important than in that case. On the other hand the law cannot be as exact as Wallich's rule governing the hatching of fish eggs, because in that case all the varying influences of the air are absent and replaced by less important ones in the water.

The law dealt with in this paper was given preliminary notice in 
bulletin 72, Bureau of Entomology, U. S. Department of Agriculture, page 20. Much additional data has been obtained since the publication of that bulletin. The work is being continued and further results will be recorded from time to time.

In discussing these papers Mr. Hooker called attention to the lantern slides exhibited by Mr. Cotton, which showed the large number of eggs deposited by the North American Fever Tick. This holds true with all Ixodid ticks, as they literally manufacture eggs from the blood with which they become engorged. Comparatively few of the seed ticks find a host, the majority dying from starvation, otherwise all animal life would be covered with ticks. The largest ticks belong to the genus Amblyomma. The gulf coast tick, Amblyomma maculatum, is the largest found in this country and when fully engorged the female measures three fourth of an inch in length. He had counted 11,265 eggs that had been deposited by a single tick of this species. The bont tick, Amblyomma hebraeum, of South Africa reaches an inch in length when fully engorged and Prof. Lounsbury estimates that a single female will deposit 20,000 eggs.

Mr. Sherman called attention to the excellent work that is being done in North Carolina by the state veterinarian, Dr. Butler. By utilizing the known facts concerning the cattle tick, twenty counties had been freed from quarantine.

Mr. J. L. Phillips remarked that conditions in Virginia are quite similar to those in North Carolina and that the quarantine line is being pushed south very rapidly.

Mr. W. D. Hunter testified to the valuable work that is being done by Dr. Butler in North Carolina, but called attention to the delicate equilibrium in which this species exists in the northern range. The problem is more difficult further south, as in Texas, where the ticks persist all winter.

Dr. Howard remarked that the Texas cattle tick is a tropical and lower austral species and that it can undoubtedly be controlled more easily when outside its normal range.

Mr. Sherman said that probably the results would be more slowly accomplished in the southern part of the state, nevertheless he considered that the results secured were exceedingly encouraging.

A paper was presented by Mr. Sanderson: 


\section{$2 \mathrm{BHL}$ Biodiversity Heritage Library}

Hunter, W. D. 1908. "A Tentative Law Relating to the Incubation of the Eggs of Margaropus annulatus." Journal of economic entomology 1(1), 51-55. https://doi.org/10.1093/jee/1.1.51a.

View This Item Online: https://www.biodiversitylibrary.org/item/37189

DOI: https://doi.org/10.1093/jee/1.1.51a

Permalink: https://www.biodiversitylibrary.org/partpdf/325764

\section{Holding Institution}

New York Botanical Garden, LuEsther T. Mertz Library

\section{Sponsored by}

The LuEsther T Mertz Library, the New York Botanical Garden

\section{Copyright \& Reuse}

Copyright Status: NOT_IN_COPYRIGHT

This document was created from content at the Biodiversity Heritage Library, the world's largest open access digital library for biodiversity literature and archives. Visit BHL at https://www.biodiversitylibrary.org. 